1. Name of the Journal: DISCOURSE \& COMMUNICATION

2. Title of the paper: 'Get me the airway there': negotiating leadership in obstetric emergencies

\title{
3. Authors
}

Polina Mesinioti ${ }^{1}$, Prof. Jo Angouri ${ }^{1}$, Dr Stephen O' brien $^{2}$, Dr Katherine Bristowe ${ }^{3}$, Dr Dimitrios Siassakos ${ }^{4}$

${ }^{1}$ Centre for Applied Linguistics, University of Warwick, UK

${ }^{2}$ Department of Obstetrics \& Gynecology, Southmead Hospital

${ }^{3}$ Cicely Saunders Institute of Palliative Care, Policy \& Rehabilitation, King's College

${ }^{4}$ Maternal \& Fetal Medicine, University College London

\section{Corresponding authors}

Polina Mesinioti, Centre for Applied Linguistics, University of Warwick, CV4 7AL, Coventry, UK

Email: P.Mesinioti@warwick.ac.uk

Tel: +44(0)24 7615 1093, Mobile: +44 (0)77 29716836

Jo Angouri, Centre for Applied Linguistics, University of Warwick, CV4 7AL, Coventry, UK

Email: J.Angouri@warwick.ac.uk

Tel: +44(0)24 76151811

5. Short title: Negotiating leadership in obstetric emergencies

6. Size: 10000 words, $3,683,118$ bytes 


\section{Autobiographical notes}

Polina Mesinioti is a $\mathrm{PhD}$ researcher at the Centre for Applied Linguistics, University of Warwick, UK. Her PhD research focuses on the enactment of professional roles in the material space in the context of obstetric emergencies. Her work is part of a larger project on teamwork in real-life obstetric emergencies (TREAT). Polina has completed her MA in Theoretical Linguistics and her BA in Linguistics at Aristotle University of Thessaloniki, Greece. Her research interests lie in discourse analysis, healthcare interaction and multimodality.

Jo Angouri is Professor and Director of Undergraduate Studies in Applied Linguistics at the University of Warwick, UK and a Visiting Distinguished Professor at Aalto University, School of Business. Her research expertise is in sociolinguistics, pragmatics and discourse analysis. She has carried out research in a range of corporate and institutional contexts and her work concerns both online and face-to-face interaction. She has published work on language and identity as well as teamwork and leadership in medical settings. Jo has recently published a monograph on Culture, Discourse, and the Workplace (Routledge, 2018) and has co-edited a volume on Negotiating Boundaries at Work (2017, EUP). Her work also includes a multidisciplinary project on migration and access to the labour market.

Stephen O'Brien is a clinician and researcher with an expertise in intrapartum obstetrics and instrumental birth. Stephen was awarded a PhD in Obstetrics and operative birth by the University of Bristol in 2018. Stephen is currently a Specialty Registrar in Obstetrics \& Gynaecology in the Severn Deanery. Stephen has received grants to conduct studies to improve performance of both obstetricians and their instruments during assisted birth, as well as looking at ways to improve care for women with complex needs in pregnancy. Prior to this work, Stephen held a prestigious National Institute for Health and Care Excellence (NICE) Scholarship. 
Katherine Bristowe is a lecturer at the Cicely Saunders Institute of Palliative Care, Policy \& Rehabilitation, King's College London. She is a mixed methodologist with a background in sociolinguistics. Her research interests include health services research specifically in the context of: advanced illness or bereavement, development and evaluation of complex interventions to improve health and social care, widening access to healthcare for LGBT communities, and improving communication between health care professionals and service users.

Dimitrios Siassakos is Reader and Honorary Consultant in Obstetrics at University College London. He is Co-Chair of the Scientific Committee of the International Stillbirth Alliance, and Simulation Adviser to the RCOG. Dimitrios is lead author of three national guidelines, Executive Editor for BJOG, and Associate Editor for BMJ Simulation. Dimitrios leads a comprehensive portfolio of research in prevention and care for stillbirth, brain injury, patient involvement in serious incident reviews, intrapartum care and operative birth, safety of maternity services, obesity in pregnancy, postpartum haemorrhage, simulation training, and technology-enhanced care. He holds grants in excess of $£ 11 \mathrm{~m}$ and has more than 100 publications including the Lancet Stillbirth Series. 


\title{
'Get me the airway there': negotiating leadership in obstetric emergencies
}

Polina Mesinioti, Prof Jo Angouri, Dr Stephen O’brien, Dr Katherine Bristowe, Dr Dimitrios Siassakos

\section{Keywords}

leadership; embodiment; multimodality; emergency care; expertise; Interactional Sociolinguistics

\begin{abstract}
The paper discusses leadership enactment in medical emergencies. We draw on video recordings of simulated obstetric emergencies and investigate how senior clinicians 'do being' the leader discursively in the spatiomaterial context of the emergency room. We take an Interactional Analysis approach, combining Conversation Analysis and Interactional Sociolinguistics and look specifically into the ways in which professional roles do interactional control using directives and questions in the material space of the obstetric room. We discuss this interactional performance in relation to the clinical performance of the teams. Our analysis shows that leadership in medical emergencies is multimodally achieved; professionals draw on discursive strategies, the affordances of material space, body, and gaze orientation which build on each other and converge in indexing leadership. Our findings highlight the situated nature of negotiating responsibility, illustrating that leadership in our context is claimed, projected and resisted discursively. We provide a typology of the functions of questions in the emergency encounter and close the paper by foregrounding the implications of our study and provide directions for further research.
\end{abstract}




\section{Introduction}

This paper is concerned with leadership negotiation in simulated obstetric emergencies. We understand medical leadership as an embodied phenomenon and we combine the wellestablished Conversation Analytic (CA) and Interactional Sociolinguistics (IS) traditions to look at how the available multimodal resources are mobilised by different professional roles in our context. In line with workplace sociolinguistic literature, we pay particular emphasis on the ways in which interactants 'do being' a leader discursively in their context (Holmes and Marra, 2004; Vine et al., 2008). The concept of doing is central in the IS/CA agenda and places emphasis on the situated and co-constructed nature of interaction. Accordingly, we discuss what leadership in the obstetric room looks like from the perspective of the clinicians. We pay special attention to the multimodal achievement of floor management. Earlier research has repeatedly shown that claiming, holding and opening/closing the floor is directly related to the enactment and resistance of power structures in workplace discourse (e.g. Angouri, 2018; ) and to the ways in which leadership is done in interaction.

Through the analysis of video recordings, we show that senior professionals 'do being' a leader multimodally; they negotiate zones of responsibility and draw on discursive strategies, material space's exploitation, body, and gaze orientation which build on each other and converge in indexing leadership. We discuss how the spatial design provides the context within which bodies act. Positioning in this context is part of claiming roles and responsibilities and we analyse movement in and out of material zones. Our discussion zooms in on the use of questions and directives which are well-studied strategies for doing interactional control and by extension leadership, particularly in hierarchical contexts such as the one we are concerned with. We focus on epistemic authority, the enactment of expertise and the ways in which professionals (attempt to) control the interaction in the material space of the maternity room. 
Our paper aims to address a critical and long overdue gap in the literature in relation to the embodiment of leadership and medical outcomes in secondary care and contributes to sociolinguistic leadership studies. In recent years, leadership in the workplace has been extensively studied by workplace sociolinguists as situated and interactionally achieved (e.g. Marra et al., 2006 and work by the NZ Language in the Workplace team), particularly in corporate settings and business meetings (e.g. Holmes and Marra, 2004). However, there is still need for research on leadership, particularly in sensitive professional encounters. In the context of healthcare, and especially in medical emergencies, which are widely under-researched, this need is even more imperative. We pay particular attention to the role of material space in the encounters and expand on the concept of zones of expertise (Sarangi and Clarke, 2002), arguing that this also involves body position and movement in the material space of the obstetric theatre.

We have organised our paper in three parts: first, we provide an overview of relevant literature, including previous research on leadership in healthcare settings, the embodiment of leadership, and directives and questions as control mechanisms. We then turn to the methodology we advocate and the analysis of our data set and finally we draw conclusions and discuss areas future studies need to address.

\section{Healthcare leadership}

Leadership studies in medical contexts have primarily focused on trauma teams. The literature has privileged the analysis of verbal communication; Jacobsson et al. (2012), for instance, examine trauma teams in emergency situations, revealing that leaders use different repertoires to convey knowledge to the team. Sarcevic et al. (2011) also examine teamwork in trauma resuscitation teams, reporting as particularly problematic 'when leadership is shared between physicians from different disciplines with different levels of experience, which often leads to 
conflict, reduces teamwork efficiency and lowers the quality of care' (2011: 236). This is directly relevant to the present study, which focuses on effective leadership in multidisciplinary medical teams.

Apart from trauma teams, research on leadership has been conducted in operating room teams. Endacott et al. (2015) examined nursing students' and registered nurses' teamwork skills whilst managing deteriorating patients. Among the themes emerged from their analysis, of relevance to our study are the leadership and followership behaviours. Specifically, although the interviews showed team members' willingness to challenge the team leader and their sense that this is acceptable, this was not visible in the video data. This underlines the need for further research on leadership negotiation in medical contexts and the importance of multimethod studies such as the one we are proposing.

Even though there is some evidence in trauma and operating teams, there is an almost complete void of studies in contexts where the patient is awake and an active member of the event. This is the case of obstetric emergencies, which our study aims to address, and it is also relevant to current debates on the embodiment of leadership which we discuss next.

\section{Leadership as embodied performance}

Despite the recent interest in discursive approaches to leadership, little attention has been paid to its embodied performance, including its material aspect. The gap is pointed out by Küpers (2013: 335), who discusses the 'prevailing marginalization [...] of the body in social, organizational and leadership theory and practice'. The significance of materiality for understanding organisational control is also pointed out by Dale (2005: 655), according to whom 'it is the social-and-material embodied actor who enacts social control'. In a more recent work, Ropo and Salovaara (2018) propose a sociomaterial approach to leadership, focusing on 
the relationship between the human and the material as embodied spatial engagement; , their understanding of space as performative and active is directly relevant to the position we take in this paper.

The embodied dimension of leadership is even more under-researched in healthcare contexts, and more specifically, in emergencies. The gap is even greater in studies taking an interactional perspective. This is intensified by the difficulties in securing access and video recording particularly in secondary health care settings; we return to this point at the very end of the paper in relation to directions of future research.

Particularly relevant to the present study is previous research on the ways space impacts on the specific context we investigate, namely medical emergencies. Siassakos et al. (2011) have identified space as a possible factor affecting clinical efficiency, reporting possible relationships between teams' clinical efficiency and: a) the number of members' exits from the labour room, and b) having a leader with a higher global situational awareness. Büscher's (2007) work brings evidence of the crucial role of embodied conduct and movement in coordinating emergency teamwork, making a relevant point that embodied behaviour is a crucial contributor to the 'economy' of interaction aimed at achieving an appropriate emergency response efficiently and swiftly. This further supports our focus on multimodality in the fastpaced environment we investigate.

Evidence on the crucial role of space has been also provided by research on operating teams; Bezemer et al. (2011) analyse interaction at the operating table and show how surgical trainers and trainees coordinate their actions using all the semiotic resources available to them. These include speech, gesture, gaze and posture, as well as the use of instruments. In the same vein, Hindmarsh et al. (2011) focus on interactions between members with different status, arguing that the investigation of interaction is difficult without taking into account the participants' embodied conducts and their mutual monitoring. Those studies' focus on members with 
different status and the ways they achieve coordination are relevant to our context, where teams also consist of staff members with different levels of seniority.

In the analysis of the data, we engage with and expand the zones of expertise concept (Sarangi and Clarke, 2002), which are demarcated by professionals through the mobilisation of discourse strategies. Sarangi and Clarke (2002: 139) claim that medical professionals delineate their (in)expertise 'through a systematic deployment of a range of modalized discourse strategies [...] while claiming authority in a limited knowledge field' and focus on how '(dis)claiming of knowledge is accomplished through the delineation of different zones of expertise' (2002: 145). We show how the discourse strategies are mobilised by the professionals in order to demarcate their zone of expertise and claim authority. Further to this, in the obstetric emergency room, epistemic authority is institutionally predefined to the senior doctor, who has the ultimate responsibility of the event. This is often associated with senior doctors' exhibition of leadership behaviours. However, the senior doctors' institutional authority does not necessarily go hand in hand with their enactment of leadership as we will show in our data; leadership is, we argue, not static but locally enacted by the senior doctor, negotiated, projected or directly challenged by other professional roles. The role is framed as agentive in our medical emergency context as it carries specific weight in the responsibility of the clinical outcome. We unpack this further through an analysis of relevant interactional features, notably directives and questions as we discuss next.

\section{Directives and questions as control devices}

Directives and questions have been widely identified as discursive control devices in the workplace. 'Directives', or 'control acts' are speech acts intended to get someone to do something; they tend to be frequent in instructions from superiors to subordinates and typically 
concern routine tasks (Holmes and Stubbe, 2015). Vine (2001) explores power by examining directives as a form used to express 'control acts', which is directly relevant to our work, as we also identify directives as a mechanism of power enactment. In a more recent work, Vine (2009) identifies imperatives as 'a direct forceful way of issuing a directive, while the use of an interrogative form, especially modal interrogatives using can or could, are much more indirect and less forceful' (2009: 1399).

Questions, in their turn, have also been studied in association with power asymmetries in professional discourse, mainly in corporate settings. Holmes and Chiles (2009), for instance, analyse questions as devices used by managers to exert control over the discourse and behaviour of people at work. Questions have also been placed at the centre of sociolinguistic decision-making research. Halvorsen (2018) reports on the strategic function of questions in an operational planning meeting, where questions drive 'the decision-making trajectory in specific directions by setting the agenda and constraining subsequent interaction' (2018: 69). In the same vein, Aritz et al. (2017) explore the performative role of the questions which are used by professionals as a way to construct their identity and establish leadership, showing how questions 'can also be used to direct team members, seize the floor, and influence decision making' (2017: 161). We consider them, therefore, appropriate for showing how professionals negotiate the nuances of their roles in a critical care setting.

Further to this, the use of questions has been related to the indication of epistemic status in interaction; Heritage (2012) examines everyday interactions and provides evidence that 'epistemic status is fundamental in determining that actions are, or are not, requests for information' (2012: 7). Similarly, Mondada (2013a) shows the way in which epistemic authority is claimed and negotiated through questions. In our work we draw on Mondada's discussion of questions as ways of claiming (or not) epistemic authority and show how different types of questions are used by professionals to both maintain role boundaries and also challenge 
senior doctors' institutional authority. We provide a typology as emerged from our work following the discussion of the data in the closing section of our paper. We now turn to the context of our study and the methodological principles we adopted.

\section{Context and Methodology}

Medical emergencies are a fast-paced work environment characterised by high pressure and where time is crucial, because of the nature of emergency. The importance of time in our context is well argued by Gillon et al. (2012: 230), according to whom there is an 'inherent risk of error related to the time-critical, high-stakes environment', and by Slade et al. (2008), who outline how the pressure of time within the emergency department impacts on patient experiences.

Another factor that adds to this particular setting's complexity, requiring investigation, is the multidisciplinary and ad hoc formation of the teams. In their study of emergency department healthcare teams, Slade et al. (2015) found little evidence of interdisciplinary collaboration, observing tensions between doctors and nurses relating to task performance and clinicians working individually and asynchronously. More, although leadership and teamwork have been extensively studied, 'much of it has focused on functions and behaviours of leaders of stable teams, such as those found in production and development teams' (Sarcevic et al., 2011: 227). Hunziker et al. (2013) review teamwork and leadership in resuscitation work and report that compared with established teams, ad hoc teams showed less leadership and a worse team performance. This provides further evidence to the importance of context in the study of leadership. Previous work by our team (Authors 2, 4 and 5) has started addressing the perceived traits of a 'good' leader in this context. Bristowe et al. (2012) investigated obstetric teams' beliefs about effective teamwork in emergency situations. In their findings, a good leader is expected to be calm, confident and not seem panicked, as 'if the person who's leading is 
panicked and shouting and chaotic then it filters through' (2012: 1386). We will show how misalignment with these ideals does come with interactional trouble in the data set.

\section{The SaFE study}

We draw our data set from a randomised controlled trial of training for obstetric emergencies (Simulation \& Fire-drill Evaluation [SaFE] Study) ${ }^{1}$, where emergencies were video recorded in six sites in the UK. There was no linguistic component in the original conceptualisation of the design and the simulated sessions were part of the regular staff training in high performing units. As such the SaFE study provided us with a rich authentic medical training context which we started analysing from a multidisciplinary angle in 2009 (e.g., Siassakos et al., 2011) and more systematically since 2016 . The data was collected and analysed following NHS ethics clearance (Author 5).

Simulations, however, have attracted significant criticism on the authenticity of context; while they are expected to function as a proxy to a real-life scenario, the participants know in advance that they perform in a simulated context. For instance, the knowledge that the actor is a patient actor, logically, affects perception of urgency and risk. This criticism is well documented in the literature and discussed by our team (see Siassakos et al., 2011), it constitutes however also a monodimensional approach. Simulations are core part of medical training and this entails that staff members are familiar, and typically comfortable, with being video-recorded for analysing their medical performance. They are authentic environments for medical teamwork and well embedded in clinical training. As such we consider them appropriate for a study of teamwork and authentic for what they are. The consistent patterns emerging from our analysis provide further support to our stance. 
In our study, teams were recorded managing a simulated obstetric emergency, eclampsia, with a scenario that included a patient-actor. Eclampsia is an obstetric emergency requiring maternity teams to perform several clinical tasks expeditiously. Its successful management in the context of this scenario includes recognition of the fit and elevated blood pressure (indicators of eclampsia), followed by the team obtaining, drawing and administering of magnesium sulphate for seizure control and secondary prevention (Siassakos et al., 2011).

The patient-actor (we use the name Lucy) was instructed to have a seizure for about 1 minute, starting 60 seconds from the end of the first handover. Staff members did not know the nature of the emergency before entering the room. They were provided with the required information through the following channels; a. a scripted handover of the standardised scenario given to the only junior midwife present in the obstetric room at the beginning of the session (this involved patient's previous symptoms and week of pregnancy); b. a partogram available in the room with the patient's information (e.g. progress of labour, dilation); c. an intercom system through which members of the evaluation team (not present in the obstetric room) provided further information (e.g. blood pressure, pulse) using the standardised script. The treatment of eclampsia is standardised and the teams were aware that their performance will be assessed.

The recorded teams were ad hoc teams; participants were randomly selected from staff lists of each unit, and then allocated to simulation teams. This ad hoc formation is the canonical form of teams in our context as 'the acute phase of obstetric emergencies is usually managed by ad hoc teams of random composition' (Bristowe et al. 2012). Teams comprised six members; one senior doctor (SD), one junior doctor (JD), two senior midwives (SM1 and SM2) and two junior midwives (JM1 and JM2). 


\section{Data set and Methods}

We draw here on eight sessions (named Case 1, 2, 3, 4, 5, 6, 7, and 8). These have been selected on the basis of a) team completeness, b) distribution of performance, and c) appropriate sound/image quality. Specifically, teams handling the emergencies are complete teams (consisting of a senior doctor, a junior doctor, two senior midwives and two junior midwives) including teams with high, low and medium clinical performance. Through the analysis of teams across the clinical ranking we provide an insight into the relationship between interactional and clinical performance.

The teams' clinical ranking is provided by the clinical team on the basis of the performance in the simulated sessions according to standard clinical criteria (time frame for the administration of magnesium sulphate). The methodology for this clinical ranking scheme is described in detail in Siassakos et al. (2010). The ranking of the sample discussed in the paper is provided in Table 1 (from best to worst clinical performance).

Table 1. Teams' clinical performance

\begin{tabular}{|c|c|c|}
\hline $\begin{array}{r}\text { Time frame for magnesium } \\
\text { administration }\end{array}$ & Cases & Score interpretation \\
\hline Magnesium administered $<5$ & Case 1, Case 2 & Good clinical \\
magnesium administered 5-6 & Case 3, Case 4, Case 5 & \\
\hline minutes & & \\
\hline Magnesium administered $>6$ & & \\
\hline
\end{tabular}




\begin{tabular}{|c|c|c|}
\hline $\begin{array}{c}\text { Magnesium drawn but not } \\
\text { administered }\end{array}$ & \\
Case 6 & \multirow{2}{*}{ Poor clinical performance } \\
drawn & Case 7, Case 8 & \\
\hline Magnesium not obtained & & \\
\hline
\end{tabular}

The sample we draw upon in this paper, consists of teams whose medical performance was evaluated both before and after training. We draw on a balanced mix of pre/post training recordings here to show the consistency of the interactional patterns we are discussing and which, as our analysis shows, were not affected by the training. Any changes in clinical practice are evidently not relevant to this paper. The analysis takes a combined CA and IS informed approach.

Our excerpts are supported by images and integrated multimodal information when this information is interpreted as significant for the participants. Our work is situated in the IS tradition which brings together the micro- (here-and-now interactions) and macro-level (broader environment within which the interactants operate). Although IS has not been traditionally used for exploring issues of power and politics, recent work revisits its affordances and makes a case for the relevance of the framework for a critical study of professional interaction (for an extensive discussion see Angouri, 2018). At the same time, the extensive CA work on floor management and turn-taking and its conceptualisation of space feed into our analysis in relation to the study of questions and directives as discussed earlier. In contrast to the IS approach, conversational analysts have discussed more extensively the importance of space and focused on its exploitation in interaction, viewing space and speech situation itself as interactively achieved. We bring the two together in the analysis of the data and suggest a 
closer dialogue between the two paradigms in line with recent work in the field (Angouri and Mondada, 2017).

Our analysis shows that claiming authority is situated in space and that senior members 'do being' the leader through mobilising the sum of semiotic resources of meaning available to them. In this paper we focus on the following:

1. positioning in material space; marking the material zone around the bed as their zone of expertise,

2. multimodally managing the interactional floor, selecting both speakers and topics using:

a. directives

b. questions

Senior members draw on these strategies to demarcate their zone of expertise, while claiming authority. Our work extends Sarangi and Clarke's (2002) concept, showing that these zones of expertise are also material. In short, positioning in space is part of claiming professional roles. We discuss these in turn below, starting with the significance of material zones in professional interaction.

\section{Material zones}

The analysis of the simulated sessions through a multimodal lens has resulted in the identification of five significant material zones in the emergency context we focus on: one out of the room and the following four in the room: left bedside, right bedside, foot of the bed, and equipment table. These are shown in Image 1.

Image 1. Main positions in the maternity room 


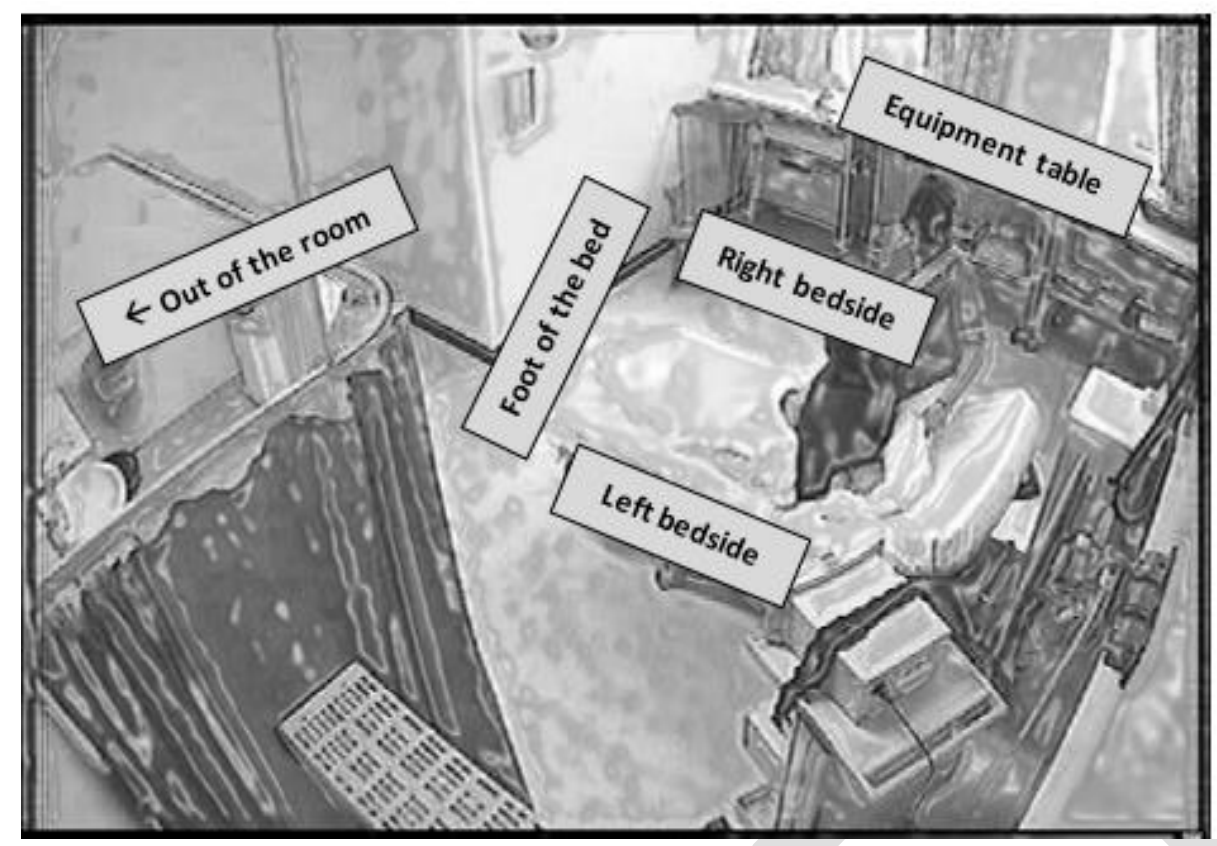

The analysis of the members' positioning and movements in relation to those zones has revealed systematic patterns among professional roles which are visualised in Image 2.

Image 2. Visual representation of professionals' material zones
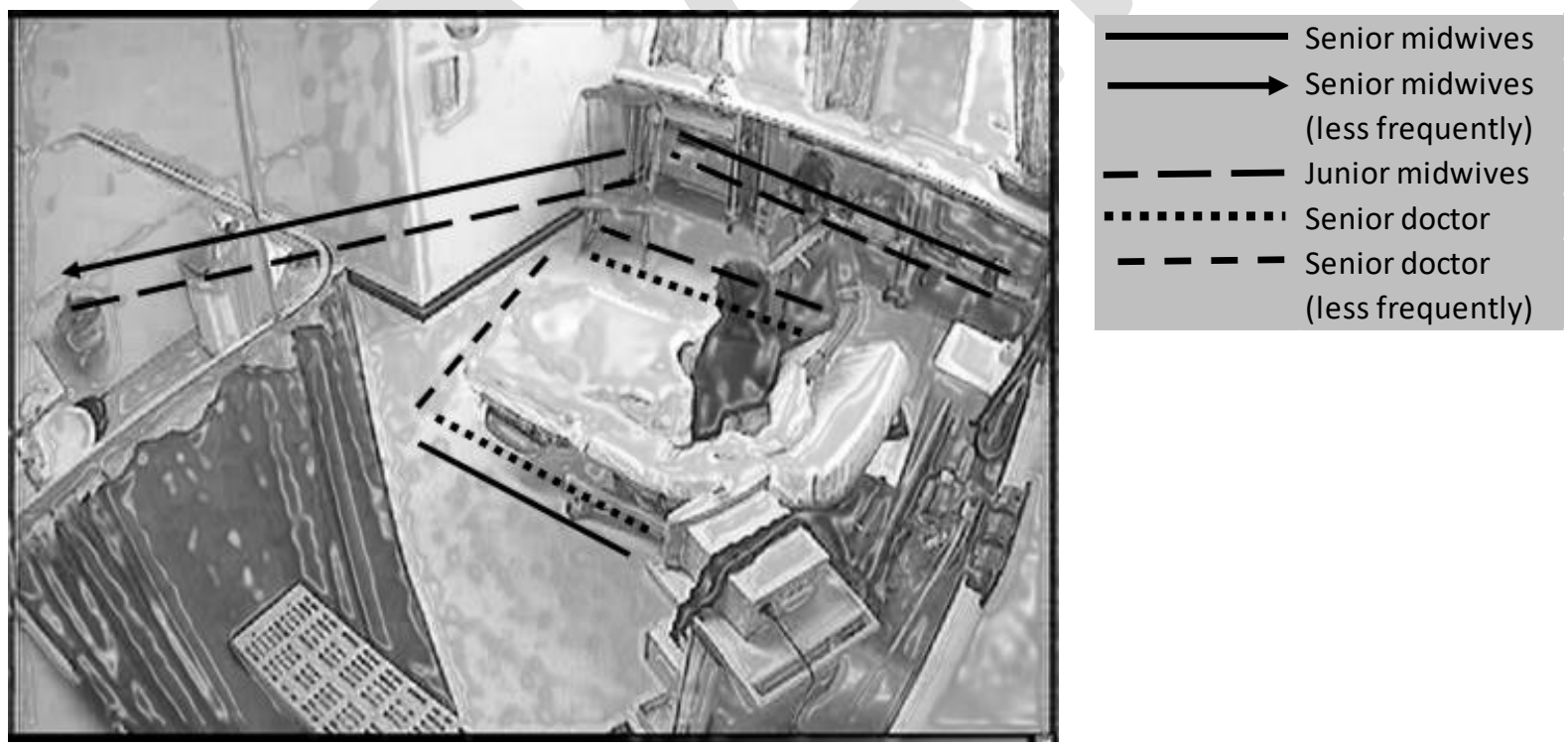

Image 2 depicts the maternity room where medical teams work and we have used lines, arrows and dashes to mark medical professionals' preferred material zones. The reason why junior doctors are not depicted in Image 2 is that in the current data they exhibit great variability in 
their multimodal behaviour and no patterns have emerged; this will be further discussed in relation to Case 5 (see also Mesinioti et al, in prep).

We show that positioning in the zones we identified constitutes part of a role claiming act and works in tandem with the verbal data. The senior doctors act in the material zone around the bed, and mostly at the bedsides, marking, in this way, the zones closer to the patient as their territory. By positioning self at the centre of the room and close to the patient, they also position self at the centre of the event. This is part and parcel of claiming epistemic authority in supervising the allocation and execution of tasks. We discuss this in detail in the following sections.

\section{Senior doctor's leadership in a team with good clinical performance}

The excerpt provided below is from Case 3, where the team scores high in the clinical performance ranking scheme (administration of magnesium within 5-6 minutes) and is illustrative of the ways leadership is enacted in our data set by senior doctors.

Excerpt 1 (Transcription conventions are provided in Appendix 1)

Instance 1

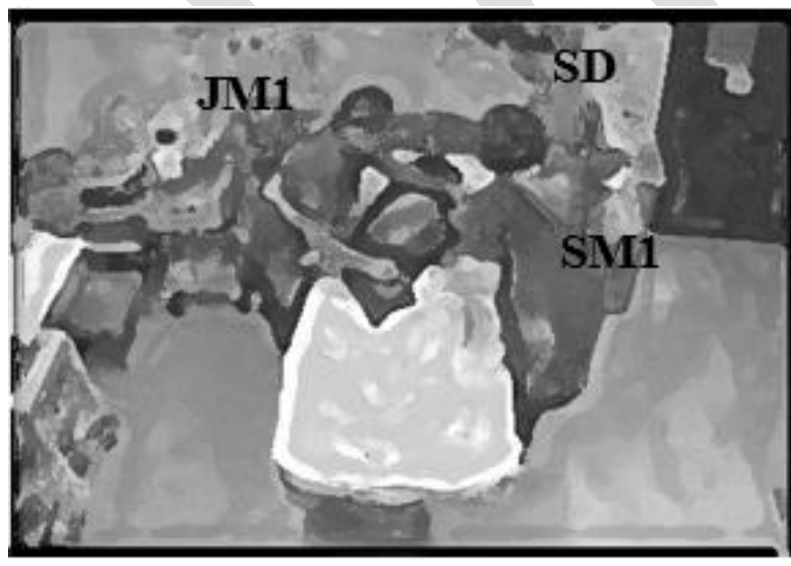

1 JM1: this is Lucy first stage term plus four and 2 she (took) oxygen she has ehm: spontaneous 3 (indec) labour-

4 SD: -get the oxygen get an airway
Instance 2

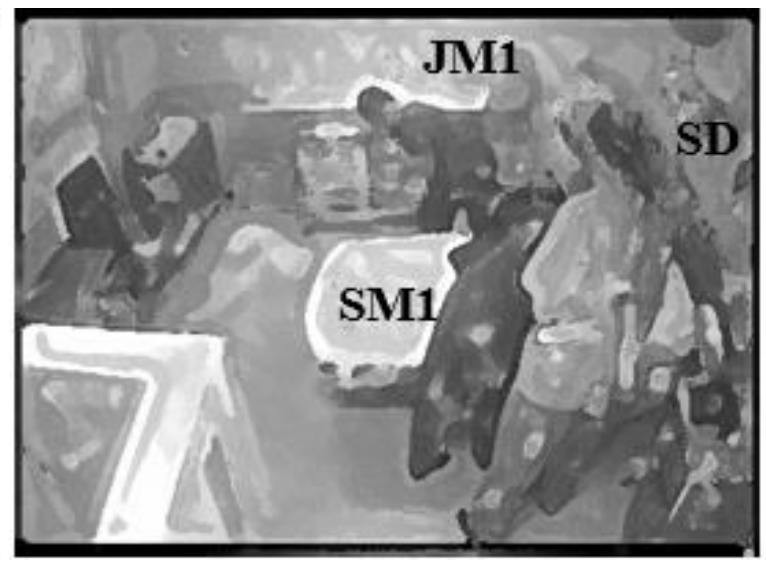

5 JM1: yeah [okay

6 SM1: [let's get her an airway 

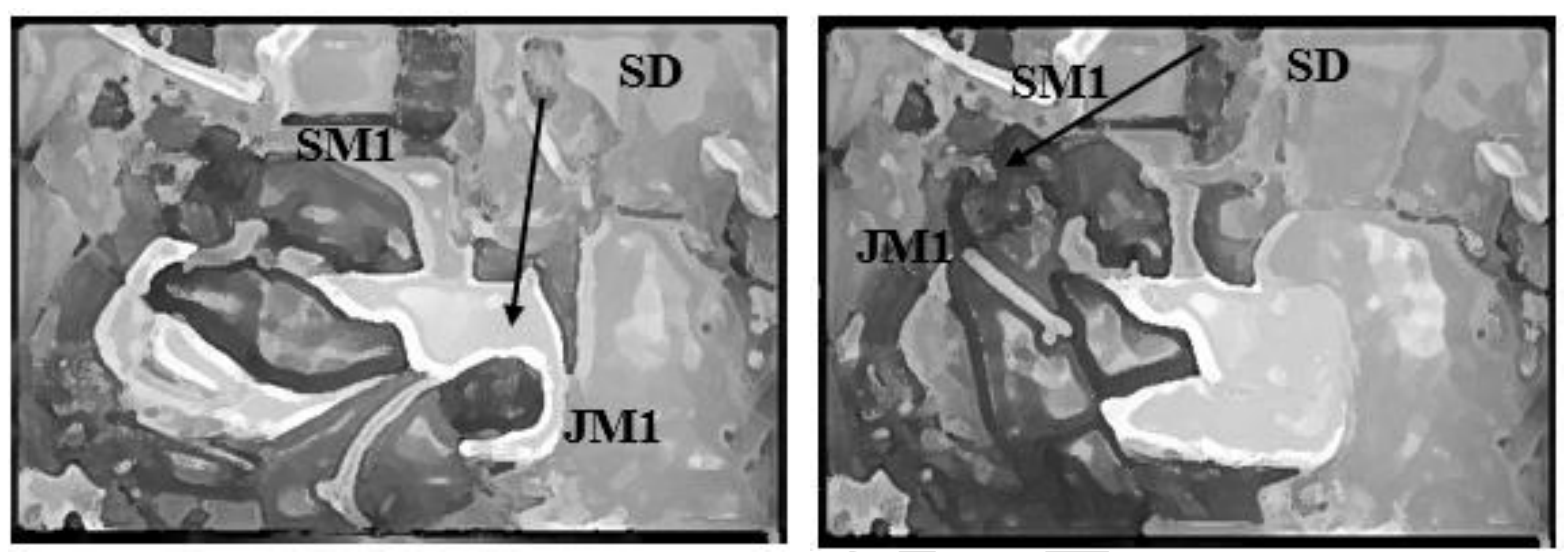

7 SD: we have the baby? $\uparrow$

8 JM1: (no) she's into spontaneous labour so $9 \quad$ [(indec)

10 SD: [okay
11 SD: get me the airway there

12 JM1: [ye:ah

$13 \mathrm{SD}$ : [that's fine

14 JM1: [(indec) and: contracting [4 to 5

$15 \mathrm{SD}$ :

16 fine

17 SM1:

18 checking her pulse-

19 SD: -and what's the blood pressure? [okay

[I'm just

In line 4 the senior doctor interrupts junior midwife 1 who updates the team regarding the patient's (Lucy) condition, taking over the floor with an unmitigated directive: get the oxygen get an airway. This interruption prevents the junior midwife from completing her turn and is used by the senior doctor for the introduction of a task allocation. Interruptions have been widely analysed from a CA perspective as speakers' means to demonstrate power, dominance and control. ${ }^{2}$ The oxygen administration task is critical in this context, as it is one of the three main tasks to be performed in eclampsia emergencies. The other two are the intravenous (IV) access task and the magnesium preparation and administration task. The significance of the oxygen-related task is linguistically indexed by the senior doctor with the paraphrase of the directive (get the oxygen get an airway) and the repetition of the verb get. Repetition is a useful strategy for intensifying directives (Holmes and Stubbe, 2015). The senior doctor uses, in line 4, the canonical form of a directive, imperative in structure. Although previous sociolinguistic 
studies have shown that superiors tend to employ politeness strategies when issuing directives to subordinates (e.g. Vine,2009), in hierarchical organisations such as hospitals, superiors' directives are often unmitigated (Saito and Cook, 2017) and the lack of mitigation is further intensified in emergency contexts.

The senior doctor's dominance is acknowledged by all the present members in the following ways: the junior midwife does not attempt to complete her utterance. Her subsequent action, in line 5 , is a responsive action, aligning with senior doctor's contribution. This alignment is indicated by the use of two response markers (yeah okay) and the instant orientation of junior midwife's body to the equipment table, in order to get the airway device. Senior midwife 1 also shows agreement with the senior doctor by echoing him in line 6: let's get her an airway.

In line 7 the senior doctor reclaims the floor with a question which is syntactically shaped as declarative with a rising intonation, seeking confirmation regarding the foetal heart rate (we have the baby? $\uparrow$ ). The senior doctor multimodally controls the floor; he selects junior midwife 1 as the next speaker by transitioning from the left bedside to the foot of the bed in order to be closer to her while at the same time he directly looks at her. The senior doctor's transitioning and body and gaze orientation succeed in opening the floor to the junior midwife, as in the next turn, she is the only one responding (line 8). Team members in our data consistently use gaze direction as a tool for the indication of the next floor holder. This is in agreement with previous research which has discussed gazing as a means of floor management and control (Mondada, 2013b).

In lines 9-10 the senior doctor briefly overlaps with the junior midwife and then gains the floor, repeating the directive of the previous instance (get me the airway), again in direct and explicit form, and allocating the task. This time, the senior doctor also accompanies his utterance with a gesture that defines the spatial deixis of there, addressing the junior midwife with verbal and gestural resources while moving back to the left bedside. With this transition and the gesture, 
the senior doctor coordinates talk with body movements in order to create interactionally shared space with respect to the projected activity (Mondada, 2009). Once again, the junior midwife acknowledges senior doctor's dominance, as she immediately performs the task while using affirmation in line 12; a prolonged ye:ah which marks agreement. In lines 17-18, senior midwife 1 also overlaps with the junior midwife and the senior doctor, with her turn aiming to introduce a new topic; I'm just checking her pulse (the senior midwife touches the patient in instance 4 performing the pulse's check). However, the senior doctor holds tight control of the floor. He manages the topical agenda by interrupting, in line 19, the senior midwife and raising a question which introduces, again, a new topic. The question here (and what's the blood pressure?) aims to request information, hence intentionally leaving the floor open.

This short excerpt illustrates common discursive strategies in our data which are mobilised by senior doctors in order to demarcate their zone of expertise. We have shown that the senior doctor manages the interactional floor with directives (lines 4,11 ) and questions (seeking confirmation in line 7, introducing a new topic in line 19). In doing so, he maintains a central position close to the patient, at the left bedside, which allows him to control the situation. These discursive strategies are achieved in a multimodal way, as he uses body and gaze direction and body movement to indicate the next possible turn-taker or the recipient of a task. The senior doctor constructs a confident persona in this episode (see unmitigated directives, interruptions, position at a central material zone) and the strategies he employs are successful, with the targeted team members aligning with him and immediately corresponding to his requests. There is no evidence of interactional trouble. This confirms our earlier findings (e.g. Bristowe et al., 2012) on how panic and noise are threatening factors for effective teamwork.

Although senior doctors institutionally have the ultimate responsibility of the event and usually 'do being' the leader' as described above, they sometimes resist responsibility discursively, as shown in the next section. 


\section{Lack of leadership in a team with poor clinical performance}

We discuss in this section two excerpts from Case 8, in which the team has scored low in terms of their clinical performance; the magnesium has been obtained but not drawn. We illustrate how the senior doctor fails to mobilise the identified discursive strategies in order to enact leadership.

Excerpt 2

Instance 1

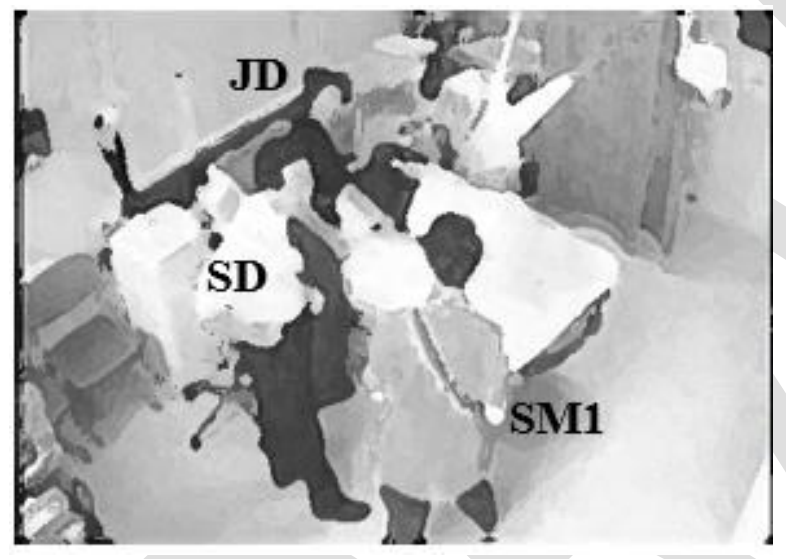

1 SM1: she just had a fit (.) e:h the blood pressure

2 was (.) what was that one $\uparrow$

3 JD: ten over fifty

4 SM1: no no much higher (.) what did they say

5 one sixty [one

6 SD: [right (.) sorry who am I?

7 (3.0) ((midwives index confusion, looking to

8 each other))

9 SD: who am I today?

10 SM1: you're mr. ((real name))

11 SD: that's al[right

12 SM1: [yeah? ((laughs))

\section{Instance 2}

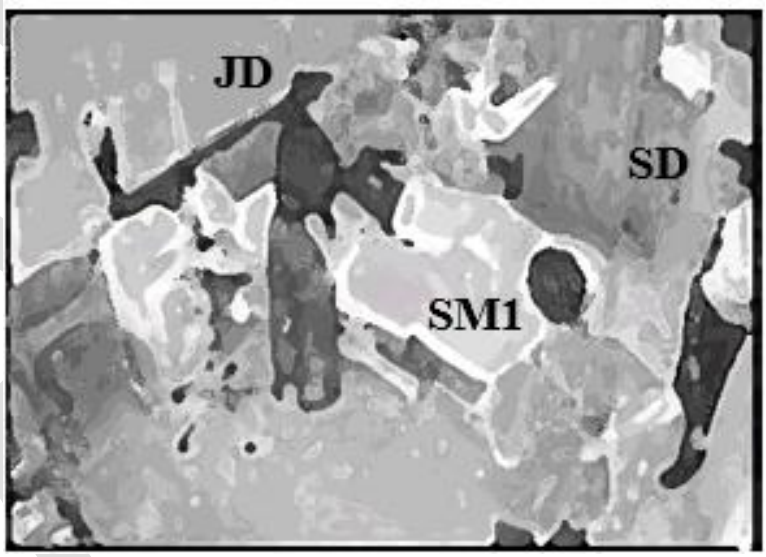

13 ((lines 13-17 are ommitted))

18 ((SD moves away from the bed))

19 SD: right (.) so remind me that again (.)

20 so she's (.)

21 ((3.0 multiple overlaps, both SM1 \& JD point 22 to somewhere))

The senior doctor enters the room quite late and positions self at the right bedside. Instead of the, typical in our data, diagnostic question which provides control of the situation, he remains silent in lines $1-5$, not coordinating the team members who struggle to update him. See, for 
example, junior doctor's and senior midwife's disagreement over the blood pressure (the measurement was provided to the team earlier through the intercom system upon request) in lines 3-4, which is not resolved. In line 6, the senior doctor interrupts during the critical stage of handover to, possibly, make a joke, which could function as a buying time mechanism here. The humourous attempt is relevant to the simulated nature of the drill: who am I?. The turn uptake shows that it is interruptive for the rest of the team members. The long three-second pause and the indexing of confusion, e.g. team looking at each other, are good signs of the need for interactional troubleshooting. In the next turn, the senior doctor self-repairs, repeating the question and adding, this time, the temporal specifier: who am I today? (line 9). In line 10, the senior midwife 1 responds without progressing with the medical task and by providing the senior doctor's real name. Team members have not been assigned different roles than their actual ones during the SaFE study. The senior doctor, for instance, would be always the senior doctor in the simulations which makes the senior doctor's question indicative of trouble as shown by the confusion in the uptake in excerpt 2 .

A few lines later (instance 2, line 18), the senior doctor moves away from the right bedside to the corner of the bed, a dispreferred locus, and stays there for the whole episode. This is markedly different to the senior doctors' tendency to orient themselves towards a central action zone, usually the bedsides. The senior doctor's utterance in lines 19-20 is a good illustration of the mitigation documented in the whole episode. The senior doctor attempts to claim the floor but his turn is prefaced by a discourse marker (right) and contains the following sequence of pauses and dispreferred linguistic cues: pause; discourse marker so to indicate a change of subject; interactionally dispreferred introduction (remind me that); pause; repetition of the discourse marker so; pause. This sequence of discourse markers, pauses and the introductory fragment remind me that again accompanied by a movement outside the central bed zone results in senior doctor's interruption by other team members who overlap with each other for 
three seconds. The uncertainty manifested in senior doctor's utterance results in interactional trouble (three seconds overlaps, simultaneous gestures by the junior doctor and the senior midwife), and it 'filters through' the whole team. This is in agreement with Bristowe et al. (2012), who discuss leader ideals, including the importance of the senior doctor being calm and confident. In this episode, these ideals are not met, as the senior doctor does not perform a confident clinical persona, and this causes interactional problems to the whole team. The interactional trouble is not only the result of the senior doctor's irregular turn in line 6; although it could be argued that the simulated nature of the emergency could lead to lack of engagement, an analysis of the use of questions and mitigation markers within the same team, illustrated below, further supports the claim.

Excerpt 3

Instance 1

Instance 2
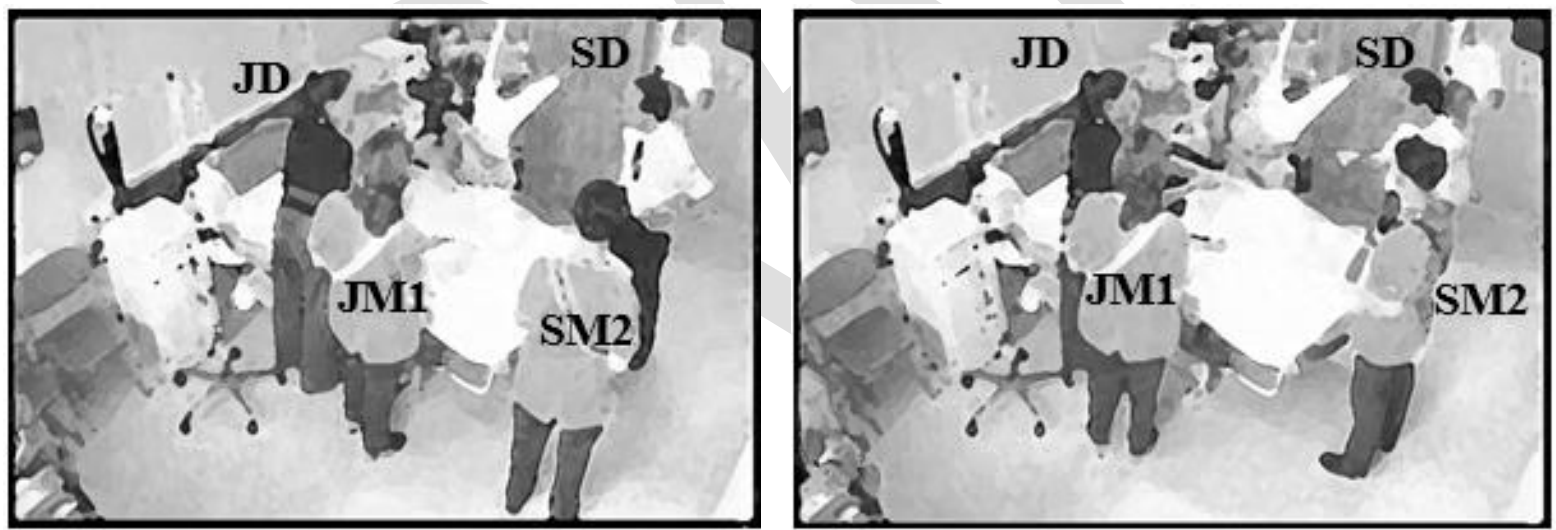

$1 \mathrm{SD}$ : right [so what was the

8 ((lines are omitted))

2 JD: $\quad$ [(I think) we cannot (.) blood pressure

9 SD: right (.) so actually (indec)?

3 recording

$4160[$ OVER 105 ((intercom system))

$5 \mathrm{JD}: \quad$ right

6 SD: a:nd the fit stopped?

7 JD: the fit stopped by itself

10 JM1: ehm: [no

$11 \mathrm{JD}: \quad$ no

12 SM2: [no

13 JM1: no we haven't tried that

14 SD: $\mathbf{m h m}$ (1.0) a:nd you: stopped the fit with 15 anything o:r?

16 JD: it stopped by itself

The questions marked in bold in lines 1, 6 and 14-15 are indicative of the questions raised by the senior doctor in this particular episode. The senior doctor's range of questions here is quite 
limited to requesting information even at later stages of the episode. As the senior doctor enters the room quite late in this case, the question about the fit (seizure) in line 6 , is in line with the diagnostic window; his mitigation throughout the episode, though, the difficulties to claim the floor and the questions which are repeated (e.g. lines 6 and 14-15) break the interaction flow and do not move the team through the stages of the emergency management. The senior doctor does not issue directives and does not take control of the situation. Questions aiming to allocate tasks are almost completely absent in the whole episode. In excerpt 3 , the senior doctor's repetitive questions eliciting information (lines 6 and 14-15) exhibit a not knowing stance and do not offer direction to the team. The senior doctor's practice results in him distancing self and resisting claiming responsibility as manifested both spatially (he acts in a rather marginal material zone, at the bed corner), and verbally; in lines 14-15, for instance, there is mitigation manifested in the repetition of the question which has already been answered in line 7 and the brief pause contained in the question.

Overall, the senior doctor seems to struggle to allocate tasks and turns and exhibits mitigation in the whole episode, failing to control the interactional floor. The non-performance of the discursive strategies we identified in the rest of our data set impacts on the whole team, leads to lack of leadership and could be relevant to the team's poor clinical performance. This confirms Sarangi and Clarke (2002: 118), who argue that 'there is the need for a demarcation of the specialist's territory and its distinction from the territories of other medical specialists', something which is not achieved in this episode.

In the case above, the uptake of the junior doctor, who, in lines 7 and 16, positions self in a knowing stance, in contrast to the senior doctor's not knowing stance is significant and in line with Mondada (2013a: 600), who argues that participants 'exploit non-congruent actions in order to resist, subvert and renegotiate their epistemic status'. We return to junior doctor's role fluidity later in the paper. Excerpt 3 clearly shows the negotiated and distributed characteristics 
of leadership even in contexts where clear hierarchies are institutionally imposed (Mesinioti et al., in prep.). This divergence between epistemic status and epistemic stance is discussed further below.

\section{Leadership enacted by other roles in a team with good clinical}

\section{performance}

In the medical context we investigate senior doctors are at the top of the institutional hierarchy. However, this does not entail that senior doctors are the only possible leaders in this setting. In our data, we find instances where other professional roles -mainly junior doctors and senior midwives- also negotiate their epistemic stance and enact leadership, by stepping into senior doctors' material zone and controlling the floor with directives and questions. Angouri (2018: 150) argues that "negotiating the boundaries of professional roles is evidently critical in any workplace' and this is exacerbated in contexts where professional roles carry critical responsibility for medical outcomes. As an illustration, we draw on Case 5, where the team scores high in the clinical assessment (magnesium administered within 5-6 minutes). Although the senior doctor does not enact leadership in the normative way we have shown, as has happened also in Case 8, in this episode leadership work is compensated by other professional roles.

Excerpt 4 


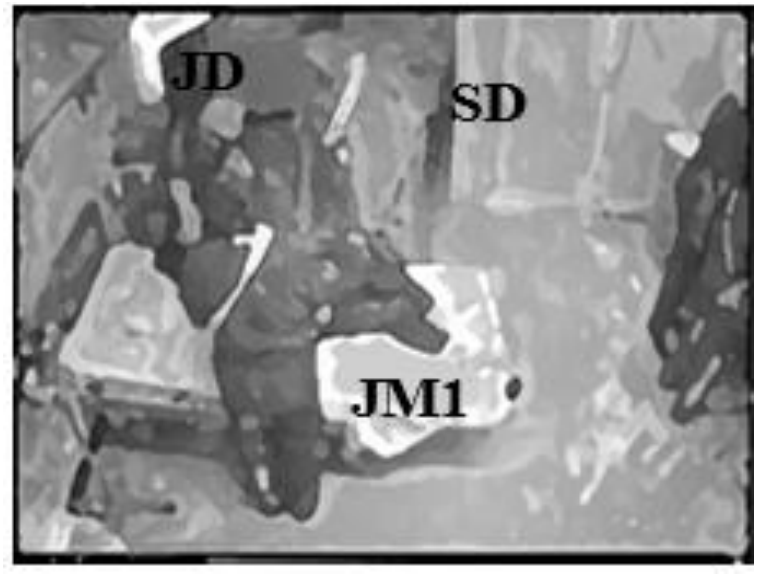

1 SD: okay and she's (.) she's not convulsing 2 anymore (.) her blood pressure was 3 JM1: one sixty over a hundred and five 4 SD: [okay

5 JD: [everything alright there Lucy ((patient))?

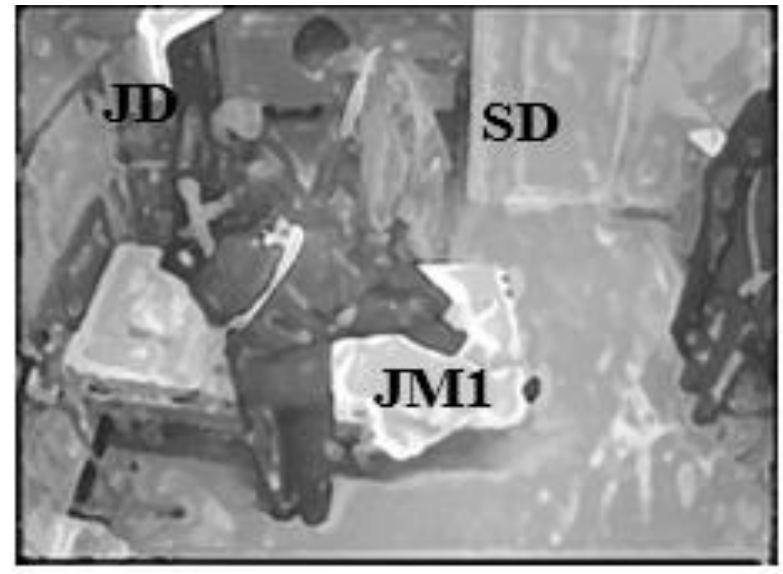

6 SD: and (.) we've got an IV in 7 ((4.0 multiple overlaps, patient mumbles)) 8 JD: yes she's responding now 9 JM1: well done Lucy

Instance 3

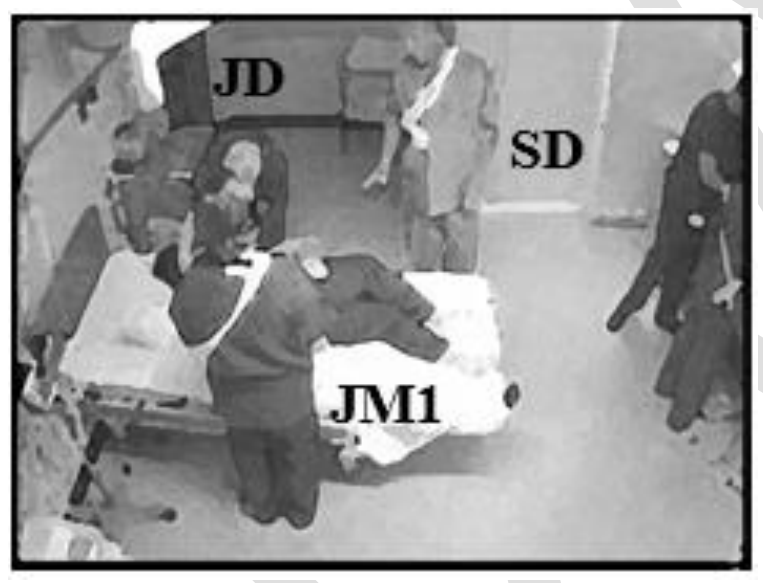

10 SD: okay (2.0) so-

11 JD: -are you in pain at all

In line 2, the senior doctor raises a question in a declarative form about the blood pressure; her blood pressure was. Junior midwife 1 responds, in line 3, as the blood pressure has been announced earlier in the excerpt through the intercom system, and the senior doctor provides an acknowledgment token in line 4 (okay). In doing so, he briefly overlaps with the junior doctor and quickly quits his turn, acknowledging the junior doctor's right to talk and not 
attempting to hold the floor with another question or directive. The junior doctor wins the floor in this overlap and raises a question to the patient (Lucy) in line 5, behaviour typical of senior doctors in our data. Junior doctors' patterns exhibit great variability, ranging from quite inactive and silent junior doctors to more active. In this particular episode, the junior doctor is quite active; this could be relevant to the fact that the senior doctor is not, and the team has to find ways to compensate for this lack of senior doctor's initiative. The variability exhibited by junior doctors could be related to the fact that junior doctors do not have fixed responsibilities; hence they are more flexible in the ways they perform their role (Mesinioti et al., in prep.).

In instance 2, the senior doctor's turn (line 6) does not result in an assessment of the situation following the canonical structure in our context, as emerged through the observations of the full data set. The pause and the lack of embodied cues (e.g., gaze or posture) that would open the floor to the next turn taker indicate the break of the interactional flow. The four second overlap in line 7 indicates that the floor management is unsuccessful, until the junior doctor manages to claim the floor and updates the team, in line 8 . This instance further confirms our stance of medical leadership as embodied, spatiomaterial practice and shows that the lack of relevant strategies has a negative impact on the floor management and overall outcomes.

The power negotiation between the senior and the junior doctor is noticeable in instance 3 , too. The senior doctor attempts to reclaim the floor in line 10 but the discourse marker okay at the beginning of his utterance followed by a long pause and the mitigating particle so delay him. This allows the junior doctor to take over the floor, interrupting the senior doctor and exhibiting, in this way, situated power. Once again, the senior doctor quickly quits his turn, accepting junior doctor's turn (line 11). In both instances 2 and 3 the senior doctor struggles to manage the floor and it is the junior doctor who steps into the leader's role and employs the relevant discursive strategies to claim control of the situation, demarcating the senior role's zone of expertise. 
The patterns shown in excerpt 4 are consistent across the whole episode; the junior doctor interrupts the senior doctor and takes over the floor particularly after the senior doctor's long pauses and mitigation markers. The junior doctor here also negotiates his epistemic stance spatially; he acts in a very central material zone, at the left bedside, maintaining a position closer to the patient than that of the senior doctor's. In doing so, he discursively accomplishes the delineation of a zone of expertise which is usually attributed to the senior doctor. Multiple readings are possible and have been debated by the team (Authors 1, 2 and 5). The senior doctor may well be relying or intending to allow the junior doctor to manage the episode. What is relevant to the discussion here is that the senior doctor's untypical leadership behaviour is compensated by the rest of the team, showing how medical leadership goes beyond institutionally predetermined roles. This is in agreement with previous research in corporate contexts (e.g. Kim and Angouri, 2019), which has shown that roles are not static but dialogically and intersubjectively constructed in interaction. This becomes clearer if we consider the use of directives and questions by other professional roles in the episode. In excerpt 5, for instance, it is junior midwife 2, senior midwife 1 and the junior doctor who attempt to coordinate action, co-constructing the role of the situated leader.

\section{Excerpt 5}

Instance 1

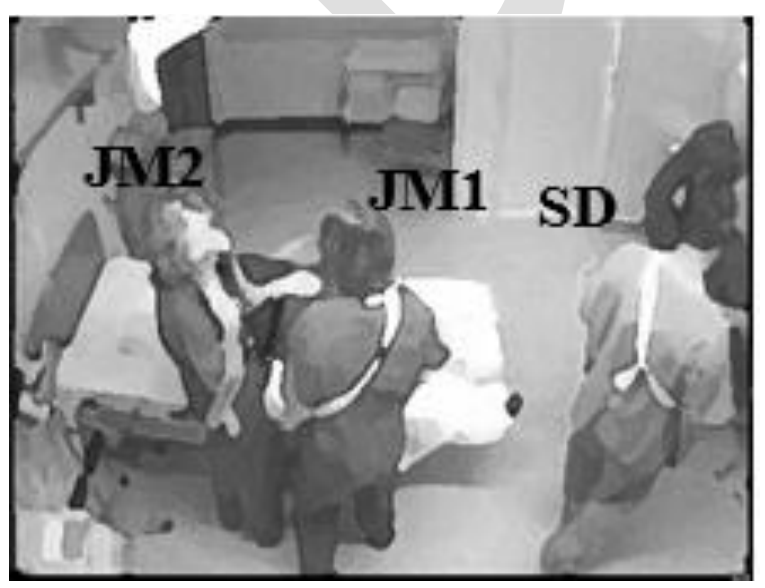

Instance 2

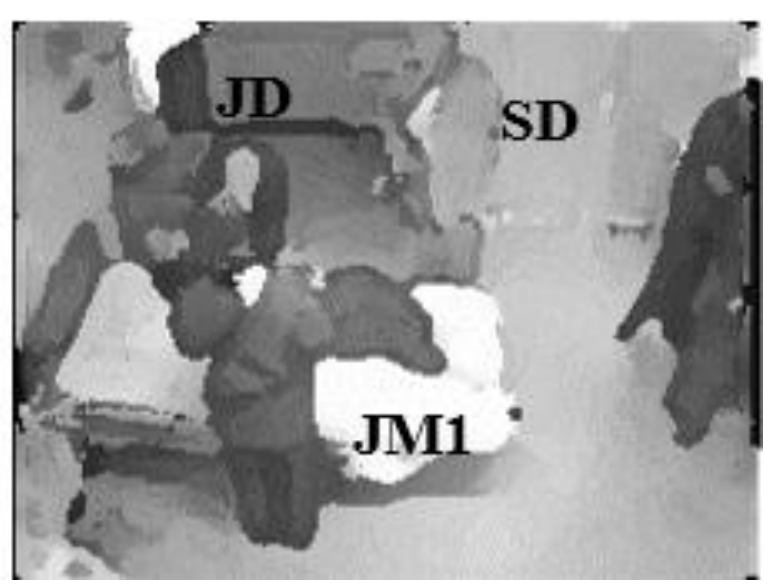


1 SD: right

2 ((3.0 multiple overlaps))

$3(1.0)$

4 JM2: Can we do a blood pressure?
5 JD: have you seen an IV (.) the IV ranitidine?

$6 \mathrm{SD}$ : IV ranitidine?

Instance 3

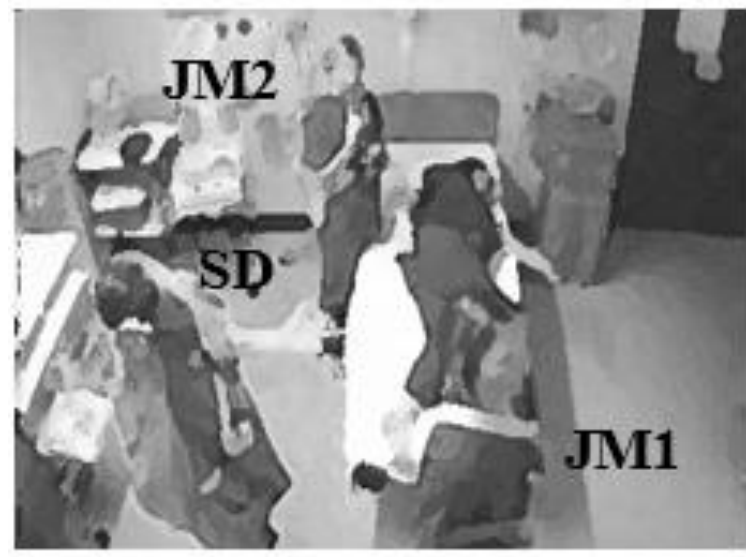

7 SM1: go to ne- [you can go into the

8 recovered (.) recovery

9 SD: $\quad$ [we should have it (.) we

10 should have it really (.) but we need

11 the anaesthetist

12 SM1: in theatre recover um: anaesthetic

13 room in the cupboard

14 JM1: OK

In line 1 , the senior doctor provides an acknowledgment token (right) which is not followed by a question or a directive, leaving the floor open to everyone in the setting. This results in long overlaps ( 3 seconds) and a pause, until junior midwife 2 claims the floor with a question aiming to issue a directive in line 4 (the blood pressure is again announced through the intercom system later in the excerpt). The question about the blood pressure reading is canonically raised by senior doctors in our data set. The collaborative action in this episode shows the team's role in doing team leadership prompted by the senior doctor's behaviour. This is also exhibited spatially; in instances 1-2 the senior doctor moves from the right bedside to the equipment trolley and back, but this transition is not justified (it does not sign a task allocation, a task performance etc.), and then he positions self in a rather marginal material zone, away from the 
bed and the equipment table. This distancing of the epicentre of action also distances him from claiming responsibility for the immediate work - note though that the responsibility still relies with him for medicolegal purposes.

In line 5, the junior doctor also raises a question which introduces a new topic directly relevant to one of the three main tasks the team needs to perform; the IV access task. The senior doctor seems confused, which is indexed by turning the head right and left and simultaneously echoing the junior doctor: IV ranitidine? The uptake indicates that this is perceived as uncertainty by the team. In instance 3, lines 7-8, the senior midwife 1 (not visible, standing by the equipment table) takes over the floor and exhibits a multimodal behaviour similar to that of a typical senior doctor; she issues a directive to junior midwife 1, targeting her as the recipient of the directive by turning her torso and looking directly at her. In doing so, she uses a less forceful form of directives with the use of a modal declarative: you can go into (Vine, 2009) and compensates for senior doctor's hesitance, bringing in the ideal of 'being confident' (Bristowe et al. 2012). In lines 7-10 senior midwife 1 overlaps with the senior doctor; this overlap is turn-competitive and is received as such, as none of them quits their turn. The senior midwife reclaims the floor and completes her utterance in lines $12-13$, issuing a directive. Her multimodal indication of the directive's recipient succeeds, as in line 14 junior midwife 1 responds in the affirmative $(O K)$, acknowledging authority. The senior doctor's mitigation, which could be the reason why directives are issued by other team members, is also noticeable in lines 9-11: his utterance contains two pauses and a repetition (we should have it (.) we should have it really (.)) before managing to state their need, which is but-prefaced (but we need the anaesthetist). The senior doctor's embodied behaviour -movements back and forth, I don't know hand gesture in instance 3- indexes possible confusion which is related to lack of control. The significance of breaking expectations of performances in clinical leadership is further discussed in the next and last section of the paper. 


\section{Revisiting 'control devices' and concluding remarks}

The professionals in our data draw on all available resources in order to carry their work and in so doing they negotiate their epistemic stance and role/responsibility that is associated and expected in their context. Seniority in the medical emergencies we studied is claimed, projected and resisted by positioning the body in a central zone, typically the senior doctors' material zone, and by managing the floor -the use of directives illustrates this. Through the analysis of our data a taxonomy of 'questions' emerged which confirms and expands previous studies (Aritz et al., 2017; Holmes and Chiles, 2010).

We summarise this in Table 2. This typology is based on the questions' functions as perceived by the interactants, shown by the uptake in the data, and the analysts' interpretations (authors 1,2 and 5).

Table 2. Emerged typology of questions

\begin{tabular}{|c|c|c|c|c|c|}
\hline $\begin{array}{l}\text { Pragmatic } \\
\text { function }\end{array}$ & $\begin{array}{c}\text { Usually } \\
\text { raised } \\
\text { by }\end{array}$ & $\begin{array}{c}\text { Question } \\
\text { type }\end{array}$ & Examples & $\begin{array}{l}\text { Linguistic } \\
\text { features }\end{array}$ & $\begin{array}{c}\text { Multimodal } \\
\text { accomplishment }\end{array}$ \\
\hline $\begin{array}{l}\text { Diagnosing/ } \\
\text { assessing the } \\
\text { situation }\end{array}$ & $\begin{array}{l}\text { Senior } \\
\text { doctors }\end{array}$ & $\begin{array}{c}\text { wh- } \\
\text { questions }\end{array}$ & $\begin{array}{c}\text { What's } \\
\text { going on? } \\
\text { What's } \\
\text { happening? }\end{array}$ & $\begin{array}{l}\text { Lack of } \\
\text { personal } \\
\text { pronouns, } \\
\text { intentionally } \\
\text { leaving the } \\
\text { floor open }\end{array}$ & $\begin{array}{l}\text { Articulatory } \\
\text { information produced } \\
\text { while transitioning in } \\
\text { the central zone (left } \\
\text { or right bedside) } \\
\text { upon entry to the } \\
\text { delivery suite }\end{array}$ \\
\hline
\end{tabular}




\begin{tabular}{|c|c|c|c|c|c|}
\hline $\begin{array}{l}\text { Allocating } \\
\text { tasks \& } \\
\text { turns/ } \\
\text { setting the } \\
\text { topical } \\
\text { agenda }\end{array}$ & $\begin{array}{l}\text { Senior } \\
\text { doctors }\end{array}$ & $\begin{array}{l}\text { polar } \\
\text { questions } \\
\text { (yes/no), } \\
\text { indirect } \\
\text { questions }\end{array}$ & $\begin{array}{l}\text { Can you give } \\
\text { me the box? } \\
\text { If you could } \\
\text { start } \\
\text { drawing up } \\
\text { the } \\
\text { infusion? }\end{array}$ & $\begin{array}{l}\text { Selection of } \\
\text { the next } \\
\text { speakers using } \\
\text { the personal } \\
\text { pronoun you } \\
\text { or proper } \\
\text { names or } \\
\text { targeting the } \\
\text { recipient } \\
\text { multimodally }\end{array}$ & $\begin{array}{l}\text { Articulatory } \\
\text { information alongside } \\
\text { the use of appropriate } \\
\text { gestures, body \& } \\
\text { gaze orientation and } \\
\text { movement for person } \\
\text { deixis } \\
\text { Setting the topical } \\
\text { agenda: Transition to } \\
\text { other material zones } \\
\text { + questions }\end{array}$ \\
\hline $\begin{array}{c}\text { Seeking } \\
\text { confirmation }\end{array}$ & $\begin{array}{l}\text { Senior } \\
\text { doctors }\end{array}$ & $\begin{array}{l}\text { questions in } \\
\text { declarative } \\
\text { syntax, } \\
\text { elliptical } \\
\text { questions, } \\
\text { rhetorical } \\
\text { questions }\end{array}$ & 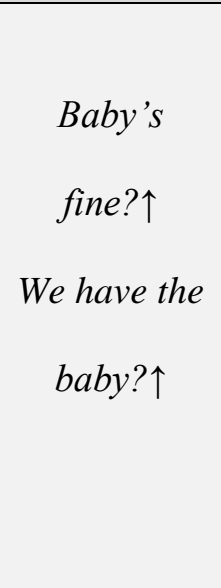 & $\begin{array}{c}\text { Rising } \\
\text { intonation }(\uparrow)\end{array}$ & $\begin{array}{c}\text { Articulatory } \\
\text { information alongside } \\
\text { appropriate gaze \& } \\
\text { body orientation to } \\
\text { indicate the next } \\
\text { speaker }\end{array}$ \\
\hline $\begin{array}{l}\text { Requesting } \\
\text { information }\end{array}$ & $\begin{array}{l}\text { Senior } \\
\text { doctors, } \\
\text { junior } \\
\text { doctors, } \\
\text { senior } \\
\text { midwives }\end{array}$ & $\begin{array}{c}\text { wh- } \\
\text { questions }\end{array}$ & $\begin{array}{l}\text { What pain } \\
\text { relief have } \\
\text { we got? } \\
\text { What's the } \\
\text { blood } \\
\text { pressure? }\end{array}$ & $\begin{array}{l}\text { Use of the } \\
\text { collective } \\
\text { pronoun we to } \\
\text { establish a } \\
\text { shared } \\
\text { identity or } \\
\text { lack of } \\
\text { personal } \\
\text { pronouns }\end{array}$ & $\begin{array}{l}\text { Lack of multimodal } \\
\text { behaviours that target } \\
\text { someone in specific, } \\
\text { intentionally leaving } \\
\text { the floor open }\end{array}$ \\
\hline
\end{tabular}




\begin{tabular}{|c|c|c|c|c|c|}
\hline Seeking & & wh- & Where shall & \\
advice/ & Junior & questions, & I put it? & & \\
clarification & midwives & how & How do I do & & \\
& & questions & it? & & \\
\hline
\end{tabular}

As shown in the excerpts, questions serve multiple functions depending on the interactional context and they are raised and achieved multimodally. Specifically, our findings indicate that senior doctors use questions in order to control the situation, allocating tasks and turns and setting the topical agenda. This is in agreement with previous literature that has discussed questions as mechanisms of interactional control (e.g. Aritz et al., 2017; Halvorsen, 2018) and as effective means of managing the agenda (Holmes and Chiles, 2010). Beyond that however, the emergent typology suggests that there are also two other types of questions raised primarily by senior doctors; questions aiming to diagnose the situation and questions seeking confirmation. These types of questions legitimise and reinforce senior doctors' power; by asking questions to diagnose the situation upon entry to the delivery suite, senior doctors (attempt to) claim control of the event early in the episode. Similarly, the data show that senior doctors are the only members seeking confirmation which reveals a different level of knowledge among the professional roles; by seeking confirmation, rather than requesting advice, for instance, senior doctors exhibit a straightforward knowing stance; this is also confirmed by the teams' uptake, as the team members almost always respond in the affirmative in these questions. If we compare this to the junior midwives, at the other end of the hierarchy spectrum, by seeking advice/ clarification they seem to exhibit a clear not knowing stance, which is tied to limited responsibility (see, for example, questions like how do I do it?). This difference between a question which is information-seeking and one which is confirmationseeking in relation to the attached level of knowledge is also discussed in Haworth (2006). In 
a context where 'knowledge' has direct effect on the clinical outcome, role claiming acts are significant for responsibility negotiation. We aim to build further on the use of questions in critical multiprofessional hospital care and expect other studies to add to this work.

Overall, the complex relationship between seniority, expertise and leadership in the medical emergency context has been shown in the analysis. Although not all senior positions are positions of leadership, the role of the senior doctor goes with institutionally formalised expectations of providing directions, training to junior members and taking medicolegal responsibility of the team's outcomes. By managing the interactional floor our medical professionals manage control over the clinical outcomes of the team.

Our findings confirm the dynamic nature of leadership and are in agreement with Mondada (2013a), who argues that, although participants tend to achieve consistency between epistemic status and epistemic stance, non-congruent actions are possible. The role of the team in 'filling in' the gaps left when senior doctors fail to take on the expected material/interactional position is important for future research to address further. On this, we found the concept of zones of expertise useful in bringing together the negotiation of role responsibility in the material zones interactants claim as well as in their linguistic behaviour. Although we specifically focused on questions and directives here, there is scope for looking into how power is communicated through a wider range of interactional features, such as interruptions. We have also shown the critical role of material zones which expands work on multimodal floor management. We discuss this further elsewhere (Mesinioti et al., in prep.). We have already shown however that different professional roles overlap with each other in the material zones of the emergency room, but they make different use of them. Senior doctors control the centre of the room and senior midwives act at the equipment table, at one of the two bedsides and exit the room frequently, but less frequently than junior midwives. Junior midwives exhibit a clear tendency to stay close to the equipment table and are the ones who exit the room most frequently in order 
to retrieve things, while one of them maintains a bedside role, passing crucial information to the team. The different use of the zones and the embodied work the professionals do compensates for the overlaps in the zones.

Zooming in on turn-taking practices, CA work has argued that interactants draw on a range of spatial and embodied resources, such as pointing, gesturing, turning toward, back and away, body torque, and gaze. Well put by Mondada (2013b: 48), the participants 'orient to the fact that their selection is related both to the organization of the current turn and to the spatial position and attention of the [chairman] ((leading interactant))'. This is also shown in our data where the verbal and non-verbal behaviour are aligned. Although we did not explicitly focused on gesture or gaze per se, further work on the relationship between verbal and non-verbal resources in medical leadership is needed to advance our understanding of the interactional context of the emergency room.

To conclude, our study consistently shows that good medical performance is inseparable from a 'good' interactional performance of the team. This general principle is by no means news to the socio/linguistic community; it is however still not widely accepted in medical literature where 'communication' (the use of the term is quite fuzzy) is often separated from team work. At the same time the importance of the material space of the emergency room has been understudied by sociolinguists and particularly workplace sociolinguists. Our field has, for a long time, prioritised verbal interaction abstracting it from its embodied, spatiomaterial context. This has served the field well and provided us with important insights on how teams work and interaction is organised. The time is ripe however for sociolinguistic studies to engage and unpack spatiomaterial performance. Going beyond our discipline, the complexity of the context we discuss here highlights the need for multidisciplinary research and a partnership between academic and non-academic teams in order to design and carry out projects that can attempt to combine linguistic analysis with a holistic view of medical practice. Our study has 
attempted to make a contribution and we hope future studies will continue building on this agenda.

\section{Notes}

1. Simulation and Fire-drill Evaluation (SaFE) Study, Department of Obstetrics and Gynaecology, North Bristol National Health Service Trust, Southmead Hospital, and University Department of Clinical Sciences at South Bristol, University of Bristol, UK.

2. This is not to suggest that all instances of overlapping talk are instances of power claiming (for a discussion see Angouri and Locher, 2012). 


\section{References}

Angouri J (2018) Culture, Discourse, and the Workplace. London: Routledge.

Angouri J and Locher M (2012) Theorising disagreement. Journal of Pragmatics 44(12): $1549-1553$.

Angouri J and Mondada L (2017) Meetings. In: Wodak R and Forchtner B (eds) The Routledge Handbook of Language and Politics. New York; Abingdon: Routledge, pp. 468-484.

Aritz J, Walker R, Cardon P, and Li Z (2017) Discourse of Leadership: The Power of Questions in Organizational Decision Making. International Journal of Business Communication 54(2): 161-182.

Bezemer J, Cope A, Kress G and Kneebone R (2011) How many lap choles have you done? A linguistic-ethnographic take on counting surgical experience. In: Angouri J, Daller M and Treffers-Daller J (eds) The Impact of Applied Linguistics. Proceedings of the 44th Annual Meeting of the British Association for Applied Linguistics. London: Scitsiugnil Press, pp. 27-30.

Bristowe K, Siassakos D, Hambly H et al. (2012) Teamwork for clinical emergencies: interprofessional focus group analysis and triangulation with simulation. Qualitative Health Research 22: 1383-1394.

Büscher M (2007) Interaction in Motion: Embodied conduct and movement in emergency teamwork. In: Mondada L (ed) Interacting Bodies. Proceedings of the 2nd Congress of the International Society for Gesture Studies. Lyon: ISGS, pp. 15-18.

Saito J and Cook H (2017) Directives in Workplace Discourse. In: Vine B (ed) The Routledge Handbook of Language in the Workplace. New York: Routledge, pp. 203-215.

Dale K (2005) Building a social materiality: Spatial and embodied politics in organizational control. Organization 12(5): 649-678. 
Endacott R, Bogossian F, Cooper S et al. (2015) Leadership and teamwork in medical emergencies: performance of nursing students and registered nurses in simulated patient scenarios. Journal of Clinical Nursing 24(1-2): 90-100.

Gillon S, Radford S, Chalwin R et al. (2012) Crisis resource management, simulation training and the medical emergency team. Critical Care and Resuscitation 14: 227-235.

Halvorsen K (2018) Questions as interactional resource in team decision making. International Journal of Business Communication 55(1): 69-93.

Haworth K (2006) The dynamics of power and resistance in police interview discourse. Discourse and Society 17(6): 739-759.

Heritage $\mathbf{J}$ (2012) Epistemics in action: Action formation and territories of knowledge. Research on Language and Social Interaction 45: 1-25.

Hindmarsh J, Reynolds P and Dunne S (2011) Exhibiting understanding: The body in apprentices. Pragmatics 43: 489-503.

Holmes J and Chiles T (2009) “Is That Right?" Questions as Control Devices in Workplace Meetings. In: Freed AF and Ehrlich S (eds) 'Why Do You Ask?': The Function of Questions in Institutional Discourse. Oxford: Oxford University Press, pp. 187-210.

Holmes J and Marra M (2004) Leadership and managing conflict in meetings. Pragmatics 14: $439-462$.

Holmes J and Stubbe M (2015) Power and Politeness in the Workplace: A sociolinguistic analysis of talk at work (2nd ed.). London: Routledge.

Hunziker S, Tschan F, Semmer N and Marsch S (2013) Importance of leadership in cardiac arrest situations: from simulation to real life and back. Swiss Medical Weekly 143: w13774. 
Jacobsson M, Härgestam M, Hultin M and Brulin C (2012) Flexible knowledge repertoires: Communication by leaders in trauma teams. Scandinavian Journal of Trauma Resuscitation and Emergency Medicine 20(1): 44.

Kim K and Angouri J (2019) 'We don't need to abide by that!': Negotiating professional roles in problem-solving talk at work. Discourse \& Communication 13(2): 172-191.

Küpers W (2013) Embodied inter-practices of leadership: Phenomenological perspectives on relational and responsive leading and following. Leadership 9(3): 335-357.

Marra M, Schnurr S and Holmes J (2006) Effective Leadership in New Zealand Workplaces: Balancing Gender and Role. In: Baxter J (ed) Speaking Out: The Female Voice in Public Contexts. Houndmills, Basingstoke: Palgrave, pp. 240-260.

Mondada L (2009) Emergent focused interactions in public places: A systematic analysis of the multimodal achievement of a common interactional space. Journal of Pragmatics 41: 1977-1997.

Mondada L (2013a) Displaying, contesting and negotiating epistemic authority in social interaction: Descriptions and questions in guided visits. Discourse Studies 15(5): 597626.

Mondada L (2013b) Embodied and spatial resources for turn-taking in institutional multi-party interactions: Participatory democracy debates. Journal of pragmatics 46(1): 39-68.

Ropo A and Salovaara P (2018) Spacing leadership as an embodied and performative process. Leadership 0(0): 1-19.

Sarangi S and Clarke A (2002) Zones of expertise and the management of uncertainty in genetics risk communication. Research on Language and Social Interaction 35: 139171. 
Sarcevic A, Marsic I, Waterhouse L et al. (2011) Leadership structures in emergency care settings: A study of two trauma centers. International Journal of Medical Informatics 80(4): 227-238.

Siassakos D, Bristowe K, Draycott T et al. (2011) Clinical efficiency in a simulated emergency and relationship to team behaviours: a multisite cross-sectional study. British Journal of Obstetrics and Gynaecology 118: 596-607.

Siassakos D, Draycott T, Crofts J et al. (2010) More to teamwork than knowledge, skill and attitude. British Journal of Obstetrics and Gynaecology 117: 1262-1269.

Slade D, Manidis M, McGregor J et al. (2015) Communicating in hospital emergency departments. Berlin; Heidelberg: Springer, Springer Nature.

Slade D, Scheeres H, Manidis M. et al. (2008) Emergency communication: the discursive challenges facing emergency clinicians and patients in hospital emergency departments. Discourse \& Communication 2(3): 271-298.

Vine B (2001) Workplace language and power: directives, requests and advice. PhD thesis, Victoria University of Wellington, New Zealand.

Vine B (2009) Directives at work: exploring the contextual complexity of workplace directives. Journal of Pragmatics 41: 1395-1405.

Vine B, Holmes J, Marra M et al. (2008) Exploring Co-leadership Talk through Interactional Sociolinguistics. Leadership 4(3): 339-360. 


\section{Appendix 1}

\section{Transcription conventions}

\begin{tabular}{|c|c|}
\hline[ & Left square brackets indicate a point of overlap onset. \\
\hline (.) & A dot in parentheses indicates a short pause. \\
\hline (X.0) & Pause about X seconds. \\
\hline$[\ldots]$ & Section of transcript omit \\
\hline$?$ & Questioning intonation. \\
\hline- & A dash indicates an interruption. \\
\hline : & Sound stretching. \\
\hline (( )) & Notes. \\
\hline$\uparrow$ & The up arrow marks rises in pitch. \\
\hline[ & Left square brackets indicate a point of overlap onset. \\
\hline (.) & A dot in parentheses indicates a short pause. \\
\hline$(\mathrm{X} .0)$ & Pause about $\mathrm{X}$ seconds. \\
\hline$[\ldots]$ & Section of transcript omitted. \\
\hline$?$ & Questioning intonation. \\
\hline- & A dash indicates an interruption. \\
\hline : & Sound stretching. \\
\hline
\end{tabular}

